\title{
Antihypertensive medication versus health promotion for improving metabolic syndrome in preventing cardiovascular events: a success rate-oriented simulation study
}

\author{
Yoichi Ohno ${ }^{1,2^{*}}$, Satomi Shibazaki ${ }^{1}$, Ryuichiro Araki ${ }^{1}$, Takashi Miyazaki ${ }^{1}$, Mayuko Hanyu' ${ }^{1}$, Makiko Satoh',
} Tsuneo Takenaka², Hirokazu Okada², Hiromichi Suzuki ${ }^{1,2}$

\begin{abstract}
Background: In practice, it is difficult to compare the effectiveness of traditional antihypertensive treatment with that of health promotion in reducing incidence rate of cardiovascular disease (IR $\mathbb{C V D}_{\mathrm{C}}$, events/year). This simulation study compared the effectiveness of two approaches to reducing $\mathbb{R}_{\mathrm{CVD}}$ in a sample population: a traditional approach, in which high-risk patients are treated with conventional antihypertensive medications, and a population-based approach, in which subjects participate in a health promotion program.

Methods: We constructed a simulation model for a sample population of middle-aged Japanese men whose systolic blood pressure (SBP) levels are normally distributed $(130 \pm 20 \mathrm{~mm} \mathrm{Hg})$. The principal assumption was that $I_{\text {CVD }}$ increases exponentially according to SBP. The population IR $\mathbb{R}_{\text {CVD }}$ was calculated as the product of the distribution of SBP multiplied by $\mathbb{R}_{\mathrm{CVD}}$ at each SBP. The cumulative $\mathbb{R}_{\mathrm{CVD}}$ was calculated by the definite integral from the lowest to the highest SBP of IR $R_{C V D}$ at each SBP level. The success rates were calculated according to SBP and metabolic risk profiles in the two approaches, respectively.
\end{abstract}

Results: The reduction in $\mathbb{R}_{\text {CVD }}$ was twice as large for antihypertensive medications as it was for health promotion in several situations. For example, if adherence to antihypertensive treatment occurred at a realistic level, the decrease in $\mathbb{R}_{\text {CVD }}$ was estimated at $9.99 \times 10^{-4}$. In contrast, even if the health program was promoted optimistically, the decrease in $\mathbb{R}_{\mathrm{CVD}}$ was estimated at $4.69 \times 10^{-4}$.

Conclusions: The success rate-oriented simulation suggests that prescribing antihypertensive medications is superior to promoting the health promotion program in reducing $\mathbb{R}_{\mathrm{CVD}}$ in virtual middle-aged Japanese men.

\section{Background}

Metabolic syndrome is a significant risk factor for the development of cardiovascular disease (CVD) in the Japanese middle-aged population [1,2]. The Japanese Ministry of Health, Labour and Welfare has recently forced health insurance organizations to provide opportunities for their members to take annual health check and health promotion programs to prevent and recover from metabolic syndrome. Some epidemiologists who

\footnotetext{
* Correspondence: yo1-ohno@bk2.so-net.ne.jp

'Community Health Science Center, Saitama Medical University, Saitama, Japan

Full list of author information is available at the end of the article
}

support the government health and welfare policy insist that a nationwide population-based approach has a greater impact on the prevention of CVDs than does a traditional approach in which antihypertensive medications are prescribed to high-risk patients (http://www. niph.go.jp/soshiki/jinzai/koroshoshiryo/tokutei/) [3,4]. People who satisfy the Japanese criteria for metabolic syndrome are advised to take the health promotion program to decrease the effects of metabolic syndrome by losing weight or reducing their waist circumference. Public health nurses, with the assistance of dietitians, exercise instructors, and occasionally regional primary physicians and industrial physicians, supervise the

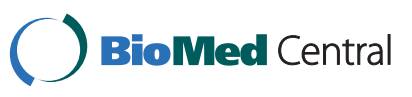

(c) 2011 Ohno et al; licensee BioMed Central Ltd. This is an Open Access article distributed under the terms of the Creative Commons Attribution License (http://creativecommons.org/licenses/by/2.0), which permits unrestricted use, distribution, and reproduction in any medium, provided the original work is properly cited. 
supporting dietary treatment and physical exercise of the program. The guidelines of the health promotion recommend patients with both metabolic syndrome and hypertension to first consult their primary physician and, after reducing their blood pressure (BP) to less than $160 / 100 \mathrm{~mm} \mathrm{Hg}$, to take the health promotion program separately $[5,6]$. In contrast, the Japanese Society of Hypertension (JSH) 2009 hypertension treatment guidelines insist that hypertensive subjects (BP > 140/90 $\mathrm{mm} \mathrm{Hg}$ ) with metabolic syndrome should visit primary physicians before initiating the health promotion. As the consequence of merging the two guidelines, the algorithm is too complicated to be familiar to primary physicians and members of health insurance organizations. Moreover, in practice it is difficult to begin the two approaches concurrently because most individuals are willing to accept only one lifestyle change at a time [7]. Therefore, our concern is which should come first: traditional antihypertensive treatment, including established lifestyle education, or vigorous lifestyle interventions. Direct evidence is still lacking with regard to the beneficial effects of lifestyle interventions (except for smoking cessation) on cardiovascular events $[8,9]$.

Epidemiological studies take several years and incur huge costs to draw conclusions about whether the health promotion program could substitute for traditional antihypertensive medications in reducing cardiovascular events. In a situation in which obvious clinical evidence is unavailable and extremely difficult, primary physicians have to decide which procedure is suitable for an individual patient with metabolic syndrome with hypertension: the traditional antihypertensive treatment or the health promotion program [3]. Simulation studies may offer patients with hypertensive metabolic syndrome and their primary physicians a possible course of action until clinical evidence becomes available [10-12]. We aimed in this simulation study to assess whether the Japanese health promotion program for improving metabolic syndrome has a large impact on the treatment of metabolic syndrome with hypertension. Should primary physicians postpone their prescriptions for antihypertensive medications, even if their patients' BP levels are higher than 140/90 mm $\mathrm{Hg}$ ? We calculated the anticipated reduction in the incidence rate of CVD ( $\mathrm{IR}_{\mathrm{CVD}}$, events/year) that would follow from conventional antihypertensive treatment and from the newly introduced health promotion program in a model population from the viewpoint of BP regulation.

\section{Methods}

\section{Calculation of the $\mathbf{I R}_{\mathrm{CVD}}$ in a sample population}

To simplify the simulation, we set a hypothetical sample population. Systolic BP $(\mathrm{SBP}=x)$ was assumed to be normally distributed and to represent the sum of the risk factors for cardiovascular complications. In other words, other risk factors, including metabolic profiles, were transferred onto the SBP level. The predictive value of metabolic syndrome for CVD is considerably determined by that level $[13,14]$. The contribution of metabolic factors to CVD is estimated as being much smaller in Japan than in Western countries [15] because the incidence of coronary heart disease in Japan is approximately $1 / 3$ of that in Western countries [5]. In the model population, the mean $(\mu)$ and the standard deviation $(\sigma)$ of the SBP levels were hypothesized to be 130 and $20 \mathrm{~mm} \mathrm{Hg}$, respectively, which were consistent with those of Japanese male subjects at 60 years of age [16]. The probability density function equals [17]

$$
f(x)=\frac{1}{\sqrt{2 \pi} \sigma} \exp \left(-\frac{(x-\mu)^{2}}{2 \sigma^{2}}\right)=\frac{1}{\sqrt{2 \pi} \times 20} \exp \left(-\frac{(x-130)^{2}}{2 \times 20^{2}}\right)
$$

Earlier epidemiological data suggested that the slope of the curve on the scattergram for the relationship between SBP and $I R_{C V D}$ was exponential [5]. $I_{C V D}$ was assumed by the following equation and based on the hypertension guidelines and epidemiological data $[16,18,19]: \mathrm{IR}_{\mathrm{CVD}}=$ $P(x)=\frac{1}{l} \exp \left(\frac{x-m}{k}\right)$, where $\mathrm{k}, \mathrm{l}$, and $\mathrm{m}$ are constants and represent the slope of the exponential curves, the absolute value of $I_{C V D}$, and the rising point from $\mathrm{e}^{0}=1$, and where simulations were performed when $\mathrm{k}=20,30$, or $40 ; 1=100$; and $m=140$. The particular numbers of the constants were adopted to be consistent with epidemiological data in Japan $[5,16]$. In this situation, the cumulative $I_{C V D}$ of the sample population is 0.01 events/year, which corresponds to a moderate risk for CVD or that of middle-aged Japanese men. These constants are influenced by risk factors such as smoking and glucose and lipid profiles. Subjects with diabetes or previous CVD are out of our scope because CVD risk assessment is different from our estimation [5]. Effects of other medications such as statin and aspirin are estimated independently from those of antihypertensive medications [20].

The cumulative $I_{C V D}$ was calculated by the definite integral from the lowest to the highest SBP of the IR $\mathrm{RVD}_{\mathrm{CV}}$ at each SBP level in the sample population [3]. The population $\mathrm{IR}_{\mathrm{CVD}}$ was evaluated as the product of distribution according to SBP multiplied by the cardiovascular event rate at each SBP (Figure 1).

The cumulative $\mathrm{IR}_{\mathrm{CVD}}$

$$
\begin{aligned}
& =\int_{L}^{H}\{f(x) \times P(x)\} d x \\
& =\int_{L}^{H}\left\{\frac{1}{\sqrt{2 \pi} \times 20} \times \exp \left(-\frac{(x-130)^{2}}{2 \times 20^{2}}\right) \times \frac{1}{l} \exp \left(\frac{x-m}{k}\right)\right\} d x
\end{aligned}
$$

Where $f(x)$ and $P(x)$ represent probability density function and $I R_{C V D}$ according to SBP, respectively. 


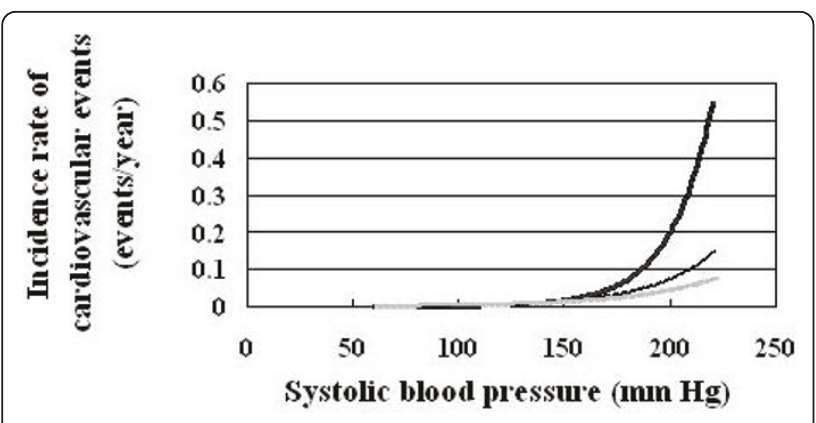

Figure 1 Relationship between systolic blood pressure (SBP) and cardiovascular event rate (IR $\left.\mathrm{R}_{\mathrm{CVD}}\right)$. $\mathrm{I}_{\mathrm{CVD}}$

$=\frac{1}{l} \exp \left(\frac{S B P-m}{k}\right)$. The thick black, thin black, and thick gray lines represent $\mathrm{k}=20,30$, and 40 , respectively, where $\mathrm{I}=100$ and $\mathrm{m}=$ 140. For example, when $k=20$, the $\mathbb{R}_{\mathrm{CVD}}$ is $0.0036 /$ year, $0.01 /$ year, and approximately $0.027 /$ year when SBP is 120,140 , and $160 \mathrm{~mm}$ $\mathrm{Hg}$, respectively, and corresponds to a moderate risk in the Japanese Society of Hypertension 2009 guidelines.

When $\mathrm{k}=20, \mathrm{l}=100, \mathrm{~m}=140$, and

$$
\begin{aligned}
& \frac{x-130}{20}=y \\
& \int_{L}^{H} f(x) \times P(x) d x=\int_{L}^{H}\left\{\frac{1}{\sqrt{2 \pi}} \times \exp \left(-\frac{y^{2}}{2}\right) \times \frac{\exp \left(y-\frac{1}{2}\right)}{100}\right\} d y \\
& \approx \int_{-\infty}^{\infty} \frac{1}{\sqrt{2 \pi}} \times \exp \left(-\frac{(y-1)^{2}}{2}\right) \times \frac{1}{100} d y=0.01
\end{aligned}
$$

\section{$\mathrm{IR}_{\mathrm{CVD}}$ after administration of antihypertensive medications}

In this simulation study, we assumed that $I_{C V D}$ after the interventions would gradually converge with $I R_{C V D}$ directly calculated from the SBP levels after the interventions. Similar to the estimates used in earlier simulation studies [3,21], CVD risk estimates after interventions were calculated by using a formula before interventions that was based on the SBP level after interventions. Risk reduction in cardiovascular complications by antihypertensive treatment is expected to reach $\sim 50 \%$ within several years [18]. Therefore, we estimated that a $50 \%$ of the decrease in SBP by the two approaches would contribute to $I R_{C V D}$ reduction in several years.

$I_{C V D}$ after administration of antihypertensive medications

$$
\begin{aligned}
& =\int_{L}^{H}\left\{f_{1}(x) \times P_{1}(x)\right\} d x \\
& =\int_{L}^{e}\left\{f_{0}(x) \times P_{0}(x)\right\} d x+\int_{e}^{H}\left\{f_{0}(x) \times P_{0}(x-g(x)) \times s(x)\right\} d x \\
& +\int_{e}^{H}\left\{f_{0}(x) \times P_{0}(x) \times(1-s(x))\right\} d x,
\end{aligned}
$$

Where $e, g(x)$, and $s(x)$ represent the SBP level at the initial administration of antihypertensive medications, the SBP-lowering effect of the antihypertensive medications and success rate of antihypertensive treatment. Antihypertensive medications were applied to hypertensive patients in the sample with an SBP > 140, 150, and $160 \mathrm{~mm} \mathrm{Hg}$. The consultation rate for medical care was estimated as a function of SBP, and the SBP-lowering effects of the antihypertensive medications were simulated in several situations. In this simulation study, beyond-BP effects that are expected in some antihypertensive medications and in the non-pharmacological treatment of the usual clinical settings were assumed to be factored into the SBP-reducing values. Beyond-BP effects in some antihypertensive medications were considered to be relatively small compared with BP lowering in preventing CVD [20]. We adopted stepwise combination medications to control SBP to the target level, if necessary, as the Japanese hypertension treatment guidelines recommend, predominantly with an angiotensin II receptor blocker and a calcium channel blocker [22].

Antihypertensive treatment constitutes at least two of the following major components: the consultation rate with primary physicians after patients are diagnosed with hypertension at the annual health check and the achievement rate in lowering BP to the target SBP level. However, few reports are available concerning these components [23], especially in Japan [24]. Moreover, the physician consultation rate for medical care after patients are diagnosed with hypertension in an annual health check program is seldom investigated in regional settings. The Japanese government mandates primary physicians to report the number of patients with certain common diseases on 1 day every 3 years. The consultation rates are estimated from the ratio of the total number of outpatients who visited medical facilities on the patient survey day to the total population of Japan (http://www.mhlw.go.jp/toukei/saikin/hw/kanja/05/0202.html). Given these circumstances, we proposed a few assumptive equations to calculate $I_{\mathrm{CVD}}$ on the basis of primary healthcare settings and earlier epidemiological investigations $[18,25]$. We adopted an exponential mathematical formula to estimate the consultation rate and the success rate in order to produce a feasible calculation in combining the normal distributions of SBP levels, considering that the consultation rate should get closer to $100 \%$ if SBP raises [26]. First, the consultation rate of primary physicians after the annual health check program for metabolic syndrome is assumed to be represented by the following equation: consultation rate (patients who visited primary physicians/patients who are diagnosed with hypertension in the annual health 
check $)=1-\exp \left(-(\mathrm{SBP}-\mathrm{a})^{*} \mathrm{~b}\right)(\mathrm{a}=$ an alarming SBP of 130, 140, and $150 \mathrm{~mm} \mathrm{Hg}$, above which patients should be concerned about their BP; and $\mathrm{b}=$ an accessibility factor to a primary physician of $0.05,0.03$, and 0.02 ) (Figure 2a). The consultation rate has a large impact on the size of the population (Figure $2 b$ ). The particular numbers of the constants were adjusted to realistic Japanese situations (approximately 20-30\%) [5,24]. Conversely, the rate without consulting a medical doctor $=$ $\exp (-(S B P-a) * b)$. Second, the SBP-lowering effect of antihypertensive medication is assumed by the following equation: SBP-lowering effect $=(\mathrm{SBP}-\mathrm{c}) * \mathrm{~d}(\mathrm{c}=$ the target SBP level of 130, 140, and $150 \mathrm{~mm} \mathrm{Hg}$; $\mathrm{d}=$ adherence for reaching the target SBP level of $0.6,0.7$, and 0.8 ) [22]. A primary physician's compliance with hypertension treatment guidelines [23] and a patient's drug adherence constitute important parts of factor " $d$ " [27]. Antihypertensive medication is simulated as being initiated from the following SBP levels: e = 140, 150, and $160 \mathrm{~mm} \mathrm{Hg}$ [28]. Earlier studies demonstrated varying levels of physician adherence to hypertension guidelines, which were usually disappointingly low. To cite a case of hypertensive patients whose SBP is $160 \mathrm{~mm} \mathrm{Hg}$, when $\mathrm{k}=20, \mathrm{l}=100$, and $\mathrm{m}=140$, the $\mathrm{IR}_{\mathrm{CVD}}$ before

a

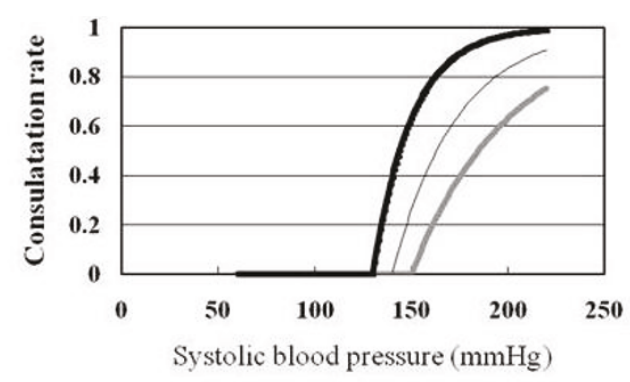

b

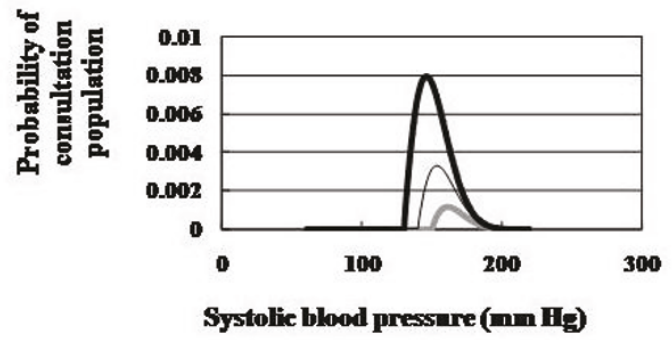

Figure 2 Relationship between systolic blood pressure (SBP) and consultations. (a) SBP and primary physician consultation rate of hypertensive patients. The consultation rate $=1-\exp (-(\mathrm{SBP}-\mathrm{a}) \times \mathrm{b})$ ( $a$ = alarming SBP level, above which patients should be concerned; $\mathrm{b}=$ the accessibility factor to a primary physician). The thick black $(a=130, b=0.05)$, thin black $(a=140, b=0.03)$, and thick gray ( $a=150, b=0.02)$ lines represent ideal, optimistic, and realistic situations, respectively. (b) SBP and probability of consultation with a primary physician. The probability equals the product of the probability density in the sample population and the consultation rate. intervention is approximately $0.027 /$ year (Figure 1 ); with an optimistic situation of $\mathrm{a}=140$ and $\mathrm{b}=0.03$, a consultation rate of 0.45 (Figure $2 \mathrm{a}$ ), and a realistic SBPlowering effect $(\mathrm{c}=140, \mathrm{~d}=0.7$, and $\mathrm{e}=150$, or [160$140] \times 0.7 \times 0.5=7 \mathrm{~mm} \mathrm{Hg}$ ), the $\mathrm{IR}_{\mathrm{CVD}}$ after antihypertensive medications is approximately $0.019 /$ year.

\section{$\mathbf{I R}_{\mathrm{CVD}}$ after health promotion}

$\mathrm{IR}_{\mathrm{CVD}}$ after heath promotion

$$
\begin{aligned}
& =\int_{L}^{H}\left\{f_{1}(x) \times P_{1}(x)\right\} d x \\
& =\int_{L}^{H}\left\{f_{0}(x) \times P_{0}(x-\alpha)\right\} d x \times \beta+\int_{L}^{H}\left\{f_{0}(x) \times P_{0}(x)\right\} d x \times(1-\beta),
\end{aligned}
$$

Where $f_{0}(x)$ and $P_{0}(x)$ represent the probability density function and $I_{C V D}$ of cardiovascular events before intervention, respectively, and $f_{1}(x)$ and $P_{1}(x)$ represent the probability density function and $\mathrm{IR}_{\mathrm{CVD}}$ of cardiovascular events after intervention, respectively. $\alpha$ and $\beta$ represent the SBP-lowering effect, including the other cardiovascular risks and the success rate of health promotion programs, respectively. We simulated the health promotion program for metabolic syndrome as being applied to the total population. The effects of the specific health promotion program on cardiovascular complications are assumed to be 5,10 , and $20 \mathrm{~mm} \mathrm{Hg}$ when they are represented as SBP-lowering effects in several years. The PREMIER trial has recently reported that lifestyle modifications for BP control (sodium reduction, weight loss, and increased physical activity) decreased $10 \mathrm{~mm} \mathrm{Hg}$ in SBP and 0.0002 events/year reduction in heart attack rate by in middle-aged, healthy, untreated individuals with prehypertension or stage I hypertension [9]. A pilot non-randomized controlled study in Japan has recently indicated that a 27 -month communitybased lifestyle approach to CVD resulted in $1 \mathrm{~mm} \mathrm{Hg}$ and $3 \mathrm{~mm} \mathrm{Hg}$ differences in SBP between the intervention and control groups for men and women, respectively [29].

The health promotion program has three support systems, stratified according to metabolic risk profiles: (1) an affirmative support system to improve the effects of metabolic syndrome continuously for 6 months (more than three close contacts with health care nurses), (2) a support system to motivate metabolic syndrome candidates to improve their health conditions (two contacts with health care nurses), and (3) a support system to offer individual information for health promotion when the results of the annual health check are sent. In the simulation, we calculated the success rates of these strategies at three levels: (1) realistic, (2) optimistic, and (3) ideal. The calculations in each scenario are summarized in Table 1. The Japanese Ministry of Health, Labour and Welfare has advocated a success rate of $10 \%$ by the 
Table 1 Success rate of health promotion programs

\begin{tabular}{lllll}
\hline & \multicolumn{2}{l}{ Support system to improve metabolic syndrome } & Indifferent to metabolic syndrome & $\boldsymbol{\Sigma}$ \\
& Affirmative campaign & Motivating campaign & Offering information & \\
\hline Realistic pattern & 10 & 20 & 50 & 20 \\
& 37.5 & 25 & 10 & 0 \\
\hline Optimistic pattern & 10 & 20 & 50 & 20 \\
& 75 & 50 & 20 & 0 \\
\hline Ideal pattern & 10 & 20 & 50 & 20 \\
& 100 & 75 & 50 & 0 \\
\hline
\end{tabular}

The upper and lower numbers in each cell represent the proportion of candidates assigned to the corresponding program and its success rate. $\Sigma$ in the rightmost column represents the total success rate, calculated as the sum of the products of the proportion of candidates assigned to the program multiplied by its success rate.

end of fiscal year 2013 (http://www.niph.go.jp/soshiki/ jinzai/koroshoshiryo/tokutei/). To cite a case of hypertensive patients whose SBP is $160 \mathrm{~mm} \mathrm{Hg}$, when we promote the health program optimistically $(\alpha=10 \mathrm{~mm}$ $\mathrm{Hg}$ ), the $\mathrm{IR}_{\mathrm{CVD}}$ after health promotion at the corresponding SBP level $(160-10 \times 0.5=155 \mathrm{mmHg})$ is 0.021 . The success rate is estimated as $\beta=0.275$ in the optimistic situation.

The comparison between the conventional BP-lowering treatment and the health promotion program for improving metabolic syndrome is based on the following two indexes: the reductions in $\mathrm{IR}_{\mathrm{CVD}}$ by the two approaches and the number of health checks $\left(\mathrm{N}_{\mathrm{HC}}\right)$ needed to decrease one cardiovascular complication per year in each approach.

$$
\mathrm{N}_{\mathrm{HC}}=\frac{1}{\int_{L}^{H} f_{0}(x) \times P_{0}(x) d x-\int_{L}^{H} f_{1}(x) \times P_{1}(x) d x},
$$

Where $f_{0}(x)$ and $P_{0}(x)$ represent the probability density function and $\mathrm{IR}_{\mathrm{CVD}}$ before intervention, respectively, and $f_{1}(x)$ and $P_{1}(x)$ represent the probability density function and $I R_{C V D}$ after intervention, respectively. After confirming the accuracy of the results by comparing the authentic definite integral method and the numerical analytical approach, we performed these calculations by using numerical analysis with $1 \mathrm{~mm} \mathrm{Hg}$ intervals.

\section{Results}

The cumulative risk reduction with traditional antihypertensive medications is demonstrated in the representative combinations of several factors, such as a, b, c, d, and $e$, when $I R_{C V D}$ is assumed to be an exponential function, or $P(x)=\frac{1}{l} \times \exp \left(\frac{x-m}{k}\right)$ (Table 2). Figure 3 demonstrates that the relationship between SBP and $I R_{C V D}$ is reduced by prescribing antihypertensive medications in virtual situations.

The cumulative risk reduction accompanied by the health promotion program is calculated in the representative combinations of several factors, such as $\alpha$ and $\beta$ (Table 3 and Figure 4).

The $\mathrm{N}_{\mathrm{HC}}$ to rescue one cardiovascular event per year is much lower for antihypertensive medications than it is for health promotions in corresponding virtual situations. For example, in the case of $\mathrm{k}=20, \mathrm{l}=100$, and $\mathrm{m}$ $=140$, if we prescribe antihypertensive medicines to patients whose SBP is not less than 150 , accessibility to the medical office is 0.03 or the usual situation, the target SBP is set to $140 \mathrm{~mm} \mathrm{Hg}$, and the success rate is $0.7, \Delta \mathrm{IR}_{\mathrm{CVD}}$ and $\mathrm{N}_{\mathrm{HC}}$ are estimated at $9.99 \times 10^{-4}$ and 1001, respectively. In contrast, even if we can promote the health program optimistically, participants reduce their body weight (BW) by $\sim 5 \mathrm{~kg}$, and their risk reduction is estimated at a $10 \mathrm{~mm} \mathrm{Hg} \mathrm{SBP-lowering} \mathrm{effect,}$ $\mathrm{IR}_{\mathrm{CVD}}$ and $\mathrm{N}_{\mathrm{HC}}$ are estimated at $4.69 \times 10^{-4}$ and 2134 , respectively.

In Figure 3 and Figure $4, \Delta \mathrm{IR}_{\mathrm{CVD}}$ is shown as the subtracted area of the $I R_{C V D}$ before and after the two approaches. Below the SBP level at which antihypertensive medications were prescribed, $\triangle \mathrm{IR}_{\mathrm{CVD}}$ at each SBP level is slightly higher in Figure 4 than in Figure 3. However, above the SBP level at which antihypertensive medications were prescribed, $\Delta \mathrm{IR}_{\mathrm{CVD}}$ at each SBP level is much higher in Figure 3 compared with the corresponding simulation curves.

\section{Discussion}

Our success rate-oriented simulation demonstrates that antihypertensive medications are more effective than the health promotion program for improving metabolic syndrome in reducing the risk of cardiovascular events. This result suggests that primary physicians should treat hypertensive patients whose SBP levels are not less than $140 \mathrm{~mm} \mathrm{Hg}$ with medications, as the traditional hypertensive guidelines recommend. Although this simulation allows a substantial role for the health promotion program in reducing cardiovascular events, risk reduction with traditional antihypertensive medications is superior. The novelty of our simulation is in 
Table 2 Reduction in cardiovascular event rate by traditional antihypertensive medications in a hypothetical population

\begin{tabular}{|c|c|c|c|c|}
\hline \multirow[t]{4}{*}{$k=20$} & $\mathrm{a}=130 \mathrm{~mm} \mathrm{Hg}$ & $\mathrm{a}=140 \mathrm{~mm} \mathrm{Hg}$ & $\mathrm{a}=150 \mathrm{~mm} \mathrm{Hg}$ & $\mathrm{a}=160 \mathrm{~mm} \mathrm{Hg}$ \\
\hline & $b=0.05$ & $b=0.03$ & $b=0.02$ & $b=0.01$ \\
\hline & $\mathrm{c}=130 \mathrm{~mm} \mathrm{Hg}$ & $\mathrm{c}=140 \mathrm{~mm} \mathrm{Hg}$ & $\mathrm{c}=150 \mathrm{~mm} \mathrm{Hg}$ & $\mathrm{c}=160 \mathrm{~mm} \mathrm{Hg}$ \\
\hline & $\mathrm{d}=0.8$ & $d=0.7$ & $d=0.6$ & $\mathrm{~d}=0.5$ \\
\hline $\mathrm{e}=140 \mathrm{~mm} \mathrm{Hg}$ & $2.33 \times 10^{-3}$ & & & \\
\hline $\mathrm{e}=150 \mathrm{~mm} \mathrm{Hg}$ & $2.08 \times 10^{-3}$ & $9.99 \times 10^{-4}$ & & \\
\hline $\mathrm{e}=160 \mathrm{~mm} \mathrm{Hg}$ & $1.56 \times 10^{-3}$ & $8.46 \times 10^{-4}$ & $4.52 \times 10^{-4}$ & \\
\hline $\mathrm{e}=180 \mathrm{~mm} \mathrm{Hg}$ & $4.51 \times 10^{-4}$ & $3.02 \times 10^{-4}$ & $1.92 \times 10^{-4}$ & $6.64 \times 10^{-5}$ \\
\hline \multirow[t]{4}{*}{$\mathrm{k}=30$} & $\mathrm{a}=130 \mathrm{~mm} \mathrm{Hg}$ & $\mathrm{a}=140 \mathrm{~mm} \mathrm{Hg}$ & $\mathrm{A}=150 \mathrm{~mm} \mathrm{Hg}$ & $\mathrm{a}=160 \mathrm{~mm} \mathrm{Hg}$ \\
\hline & $b=0.05$ & $b=0.03$ & $b=0.02$ & $b=0.01$ \\
\hline & $\mathrm{c}=130 \mathrm{~mm} \mathrm{Hg}$ & $\mathrm{c}=140 \mathrm{~mm} \mathrm{Hg}$ & $\mathrm{c}=150 \mathrm{~mm} \mathrm{Hg}$ & $\mathrm{c}=160 \mathrm{~mm} \mathrm{Hg}$ \\
\hline & $\mathrm{d}=0.8$ & $d=0.7$ & $d=0.6$ & $\mathrm{~d}=0.5$ \\
\hline$e=140$ & $1.13 \times 10^{-3}$ & & & \\
\hline$e=150$ & $9.68 \times 10^{-4}$ & $4.24 \times 10^{-4}$ & & \\
\hline$e=160$ & $6.74 \times 10^{-4}$ & $3.42 \times 10^{-4}$ & $1.76 \times 10^{-4}$ & \\
\hline$e=180$ & $1.58 \times 10^{-4}$ & $1.01 \times 10^{-4}$ & $6.26 \times 10^{-5}$ & $2.06 \times 10^{-5}$ \\
\hline \multirow[t]{4}{*}{$\mathrm{k}=40$} & $\mathrm{a}=130 \mathrm{~mm} \mathrm{Hg}$ & $\mathrm{a}=140 \mathrm{~mm} \mathrm{Hg}$ & $\mathrm{A}=150 \mathrm{~mm} \mathrm{Hg}$ & $\mathrm{a}=160 \mathrm{~mm} \mathrm{Hg}$ \\
\hline & $b=0.05$ & $b=0.03$ & $b=0.02$ & $b=0.01$ \\
\hline & $c=130$ & $c=140$ & $c=150$ & $c=160$ \\
\hline & $d=0.8$ & $d=0.7$ & $d=0.6$ & $d=0.5$ \\
\hline$e=140$ & $7.32 \times 10^{-4}$ & & & \\
\hline$e=150$ & $6.14 \times 10^{-4}$ & $2.58 \times 10^{-4}$ & & \\
\hline$e=160$ & $4.11 \times 10^{-4}$ & $2.02 \times 10^{-4}$ & $1.02 \times 10^{-4}$ & \\
\hline$e=180$ & $8.66 \times 10^{-5}$ & $5.40 \times 10^{-5}$ & $3.31 \times 10^{-5}$ & $1.06 \times 10^{-5}$ \\
\hline
\end{tabular}

Abbreviations: $\mathrm{k}=$ constant determining the slope of the exponential curve between systolic blood pressure and cardiovascular incidence rate; $\mathrm{I}=$ constant related to absolute value of cardiovascular incidence rate of $100 ; \mathrm{m}=$ constant determining the slope of the exponential curve to be $\mathrm{e}^{0} / \mathrm{l}$ of 140 ; $\mathrm{a}=\mathrm{an}$ alarming SBP of $130,140,150$, and $160 \mathrm{~mm} \mathrm{Hg}$, above which patients should be concerned about their BP; $b=$ an accessibility factor to a primary physician of $0.05,0.03$, 0.02 , and $0.01 ; c=$ the target SBP level of 130,140, 150, and $160 \mathrm{~mm} \mathrm{Hg} ; \mathrm{d}=$ adherence for reaching the target SBP level of $0.5,0.6,0.7$, and $0.8 ; \mathrm{e}=\mathrm{SBP}$ level of $140,150,160$, or $180 \mathrm{~mm} \mathrm{Hg}$ from which administration of antihypertensive medications was initiated.

the estimation of success rates for both approaches, although we used several ambitious assumptions. The consultation rate has a large impact on reducing cardiovascular events through the prescription of antihypertensive medications.

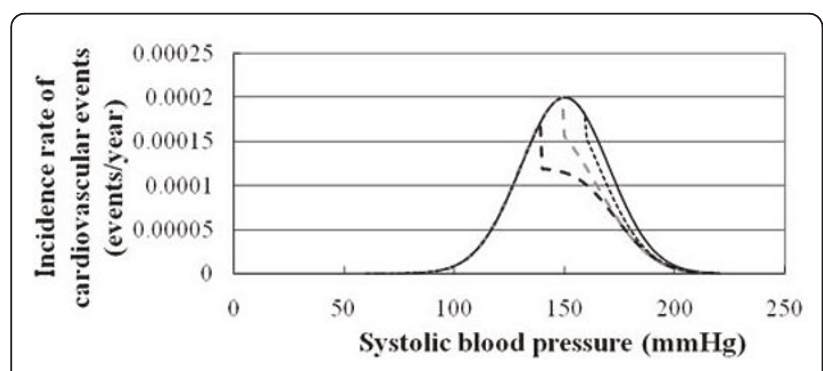

Figure 3 Relationship between systolic blood pressure and cardiovascular event rate before and after prescribing traditional antihypertensive medications. The solid black, dotted black (>160 mm Hg), dashed grey (>150 mm Hg), and dashed black (>140 $\mathrm{mm} \mathrm{Hg}$ ) lines represent no antihypertensive treatment and realistic, optimistic, and ideal antihypertensive treatments, respectively. The area between the solid black line and the corresponding line represents the reduction in the incidence rate of cardiovascular events.
The population-based approach to the prevention of cardiovascular events by improving metabolic syndrome may be more unsatisfactory than expected for several reasons: (1) The risk reduction of health promotion for improving metabolic syndrome in CVD might be underestimated. We took the BP-lowering effect of health promotion to improve metabolic syndrome into account for reducing cardiovascular complications. The BP-lowering effect by reducing $B W$ is estimated at 1 to $2 \mathrm{~mm}$ $\mathrm{Hg} / \mathrm{kg} \mathrm{BW}$ loss $[5,25,30]$. The effect of the health promotion program on lowering SBP is limited, and the effect on reducing risk might be beyond what we anticipated $[25,31-33]$. The health promotion program can reduce the risk of cardiovascular complications through pathways without lowering BP. For example, weight loss improves metabolic factors such as glucose and lipid profiles [8,34], and physical activity can inhibit the production of reactive oxygen species [35]. In addition, the beneficial effects of the interaction between lowering BP and metabolic factors in inhibiting cardiovascular events may go beyond what we anticipated. (2) The risk of cardiovascular events increases exponentially with SBP elevation. For this assumption, the sum of the risk of 
Table 3 Reduction in incidence rate of cardiovascular events per year by the health promotion program in a hypothetical population

\begin{tabular}{clll}
\hline $\mathrm{k}=20$ & $\alpha=20 \mathrm{~mm} \mathrm{Hg}$ & $\alpha=10 \mathrm{~mm} \mathrm{Hg}$ & $\alpha=5 \mathrm{~mm} \mathrm{Hg}$ \\
\hline$\beta$ ideal & $1.35 \times 10^{-3}$ & $8.52 \times 10^{-4}$ & $4.92 \times 10^{-4}$ \\
$\beta$ optimistic & $7.42 \times 10^{-4}$ & $\mathbf{4 . 6 9 \times 1 0 ^ { - 4 }}$ & $\mathbf{2 . 7 1 \times 1 0 ^ { - 4 }}$ \\
$\beta$ realistic & $3.71 \times 10^{-4}$ & $\mathbf{2 . 3 4 \times 1 0 ^ { - 4 }}$ & $\mathbf{1 . 3 5 \times 1 0 ^ { - 4 }}$ \\
\hline $\mathrm{k}=30$ & $\alpha=20 \mathrm{~mm} \mathrm{Hg}$ & $\alpha=10 \mathrm{~mm} \mathrm{Hg}$ & $\alpha=5 \mathrm{~mm} \mathrm{Hg}$ \\
\hline$\beta$ ideal & $8.40 \times 10^{-4}$ & $5.05 \times 10^{-4}$ & $2.90 \times 10^{-4}$ \\
$\beta$ optimistic & $4.62 \times 10^{-4}$ & $\mathbf{2 . 7 8 \times 1 0 ^ { - 4 }}$ & $\mathbf{1 . 5 9 \times 1 0 ^ { - 4 }}$ \\
$\beta$ realistic & $2.31 \times 10^{-4}$ & $\mathbf{1 . 3 9} \times \mathbf{1 0}^{-4}$ & $\mathbf{7 . 9 7 \times 1 0 ^ { - 5 }}$ \\
\hline $\mathrm{k}=40$ & $\alpha=20 \mathrm{~mm} \mathrm{Hg}$ & $\alpha=10 \mathrm{~mm} \mathrm{Hg}$ & $\alpha=5 \mathrm{~mm} \mathrm{Hg}$ \\
\hline$\beta$ ideal & $6.31 \times 10^{-4}$ & $3.72 \times 10^{-4}$ & $2.16 \times 10^{-4}$ \\
$\beta$ optimistic & $3.47 \times 10^{-4}$ & $\mathbf{2 . 0 5 \times 1 0 ^ { - 4 }}$ & $\mathbf{1 . 1 9 \times 1 0 ^ { - 4 }}$ \\
$\beta$ realistic & $1.74 \times 10^{-4}$ & $\mathbf{1 . 0 2 \times 1 0 ^ { - 4 }}$ & $\mathbf{5 . 9 3 \times 1 0 ^ { - 5 }}$ \\
\hline
\end{tabular}

Abbreviations: $\mathrm{k}=$ constant determining the slope of the exponential curve between systolic blood pressure and cardiovascular incidence rate; $\mathrm{I}=$ constant related to absolute value of cardiovascular incidence rate of $100 ; \mathrm{m}$ $=$ constant determining the slope of the exponential curve to be $\mathrm{e}^{0} / \mathrm{I}$ of 140 ; $\alpha=$ SBP-lowering effect ( $\mathrm{mm} \mathrm{Hg}$ ), including the other cardiovascular risks; $\beta=$ success rate of health promotion program.

cardiovascular complications at SBP levels of less than $140 \mathrm{~mm} \mathrm{Hg}$ is small even when the slope of the curve for the relationship between $S B P$ and $I_{C V D}$ is low. In other words, BP is an excellent predictor of CVD, especially in Japan, where stroke has been more prevalent than ischemic heart disease. Hypertension is a determinant component in Japanese men with metabolic syndrome for predicting cardiovascular complications [36].

One criticism of our model is that the estimation of both approaches may be too optimistic. Only a few researchers have reported the consultation rate in a general Japanese population [24].

Another assumption of our model relates to adherence of the primary physician to the hypertensive treatment guidelines and the patients' adherence to

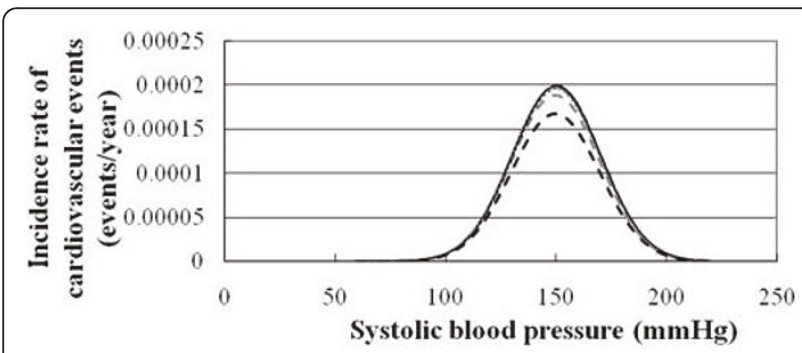

Figure 4 Relationship between systolic blood pressure and cardiovascular event rate before and after promoting health promotion programs. The solid black, dotted grey, dashed black, and dashed gray lines represent no health promotion program and realistic, optimistic, and ideal health promotion programs,

respectively. The area between the solid black line and the corresponding line represents the reduction in cardiovascular event rates. The solid black line overlaps the dotted grey line considerably. medication. The success rate of antihypertensive treatment, according to the Japanese antihypertensive treatment guidelines, is reported to be 30 to $60 \%[37,38]$. We assumed that $I R_{C V D}$ after the interventions will gradually converge with $\mathrm{IR}_{\mathrm{CVD}}$ directly calculated from the SBP levels after the interventions, as shown in another simulation [21]. This estimation is based on the guidelines and the evidence derived from largescale clinical investigations and long-term follow-up studies $[5,18,39]$.

One question about our model concerns what would happen if traditional antihypertensive medications and the health promotion program were administered concurrently. If the effects of both approaches are independent, then the overall effect of both approaches is the difference between the sum and the product of each approach. However, this assumption is too robust to adopt because most hypertensive patients with metabolic syndrome might be encouraged to lose weight in the medical office of the outpatient department, the usual clinical setting, not as part of a health promotion approach offered by a health nurse. In addition, the success rate of the health promotion program will decrease if patients are satisfied with the reduction in SBP as a result of taking antihypertensive medications. Most individuals are willing to accept only one approach at a time [7]. These factors greatly interfere with the independency of both approaches.

Another question relates to why we boldly assumed the transfer of metabolic risk factors onto SBP levels. There are few reports available that address how to transfer metabolic risk factor onto SBP levels. The estimation of the relationship between the SBP levels and $I R_{C V D}$ is a key factor in assessing these issues. In the simulation model, the absolute value of $I R_{C V D}$ related to factor "l" does not influence the results of the simulation. A sensitive question is whether traditional antihypertensive medications are more effective if we restricted the subjects whose SBP levels are within the high normal range $(130-139 \mathrm{~mm} \mathrm{Hg}$ ) from the model. The superiority of the medication would become unclear in the high normal SBP range (data not shown).

Many undefined issues in preventive medicine emerge from this pioneer simulation study. In future, the consultation rate and medication adherence in various situations should be investigated vigorously. This study indicates that the consultation rate has a tremendous impact on $I R_{C V D}$ in a high-risk approach. We propose that two components are related to the consultation rate: awareness of hypertension and accessibility to medical care. However, many other factors and relations such as cost-effectiveness, economic status, and preventive health information need to be explored. 


\section{Conclusions}

A traditional approach of using antihypertensive treatment is superior to the health promotion approach for improving metabolic syndrome by reducing the risk of cardiovascular events in a sample population of middle-aged Japanese men. However, the health promotion approach also has a substantial impact on reducing cardiovascular events if success rate is satisfactory in this group.

\section{Author details}

${ }^{1}$ Community Health Science Center, Saitama Medical University, Saitama, Japan. ${ }^{2}$ Department of Nephrology, Saitama Medical University, Saitama, Japan.

\section{Authors' contributions}

YO did all aspects of this research. SS, RA, and TM wrote the epidemiological part of the draft. MH and MS analyzed the effect of the population approach. $\mathrm{T}, \mathrm{HO}$, and $\mathrm{HS}$ analyzed the effect of the high-risk approach. All authors read and approved the final manuscript.

\section{Competing interests}

The authors declare that they have no competing interests.

Received: 31 May 2010 Accepted: 13 February 2011

Published: 13 February 2011

\section{References}

1. Ninomiya T, Kubo M, Doi Y, Yonemoto K, Tanizaki Y, Rahman M, Arima H, Tsuryuya K, lida M, Kiyohara Y: Impact of metabolic syndrome on the development of cardiovascular disease in a general Japanese population: the Hisayama study. Stroke 2007, 38(7):2063-2069.

2. Chiba Y, Saitoh S, Takagi S, Ohnishi H, Katoh N, Ohata J, Nakagawa M, Shimamoto K: Relationship between visceral fat and cardiovascular disease risk factors: the Tanno and Sobetsu study. Hypertension Research 2007, 30(3):229-236.

3. Law MR, Frost CD, Wald NJ: By how much does dietary salt reduction lower blood pressure? III-Analysis of data from trials of salt reduction. Brit Med J 1991, 302(6780):819-824.

4. Funahashi T, Matsuzawa Y: Metabolic syndrome: clinical concept and molecular basis. Ann Med 2007, 39(7):482-494.

5. Ogihara T, Kikuchi K, Matsuoka H, Fujita T, Higaki J, Horiuchi M, Imai Y Imaizumi T, Ito S, Iwao H, Kario K, Kawano Y, Kim-Mitsuyama S, Kimura G, Matsubara H, Matsuura H, Naruse M, Saito I, Shimada K, Shimamoto K, Suzuki H, Takishita S, Tanahashi N, Tsuchihashi T, Uchiyama M, Ueda S, Ueshima H, Umemura S, Ishimitsu T, Rakugi H: The Japanese Society of Hypertension Guidelines for the Management of Hypertension (JSH 2009). Hypertension Research 2009, 32(1):3-107.

6. Kokubo Y, Kamide K: High-normal blood pressure and the risk of cardiovascular disease. Circ J 2009, 73(8):1381-1385.

7. Pickering TG: Lifestyle modification and blood pressure control: is the glass half full or half empty? JAMA 2003, 289(16):2131-2132.

8. Dagogo-Jack S, Egbuonu N, Edeoga C: Principles and practice of nonpharmacological interventions to reduce cardiometabolic risk. Med Princ Pract 2010, 19(3):167-175.

9. Elmer PJ, Obarzanek E, Vollmer WM, Simons-Morton D, Stevens VJ, Young DR, Lin PH, Champagne C, Harsha DW, Svetkey LP, Ard J, Brantley PJ, Proschan MA, Erlinger TP, Appel LJ: Effects of comprehensive lifestyle modification on diet, weight, physical fitness, and blood pressure control: 18-month results of a randomized trial. Ann Intern Med 2006, 144(7):485-495.

10. Russell $L B$, Valiyeva $E$, Carson JL: Effects of prehypertension on admissions and deaths: a simulation. Arch Intern Med 2004, 164(19):2119-2124.

11. Turner MJ, van Schalkwyk JM: Blood pressure variability causes spurious identification of hypertension in clinical studies: a computer simulation study. Am J Hypertens 2008, 21(1):85-91.

12. Mannan HR, Knuiman M, Hobbs M: Adapting a Markov Monte Carlo simulation model for forecasting the number of coronary artery revascularization procedures in an era of rapidly changing technology and policy. BMC Med Inform Decis Mak 2008, 8:27.

13. Obara F, Saitoh S, Takagi S, Shimamoto K: Influence of hypertension on the incidence of cardiovascular disease in two rural communities in Japan: the Tanno-Sobetsu study. Hypertens Res 2007, 30(8):677-682.

14. Mozaffarian D, Kamineni A, Prineas RJ, Siscovick DS: Metabolic syndrome and mortality in older adults: the Cardiovascular Health Study. Arch Intern Med 2008, 168(9):969-978.

15. Lida M, Ueda K, Okayama A, Kodama K, Sawai K, Shibata S, Tanaka S, Keijnkai T, Horibe H, Minowa M, Yanagawa H, Hashimoto T: Impact of elevated blood pressure on mortality from all causes, cardiovascular diseases, heart disease and stroke among Japanese: 14 year follow-up of randomly selected population from Japanese - Nippon data 80 . J Hum Hypertens 2003, 17(12):851-857.

16. Okayama A, Kadowaki T, Okamura T, Hayakawa T, Ueshima H: Age-specific effects of systolic and diastolic blood pressures on mortality due to cardiovascular diseases among Japanese men (NIPPON DATA80). J Hypertens 2006, 24(3):459-462

17. Armitage P, Berry G, Matthews JNS: Probability. In Statistical Methods in Medical Research. 4 edition. Edited by: Armitage P, Berry G, Matthews JNS. London: Blackwell Publishing; 2002:47-82.

18. Whitworth JA: 2003 World Health Organization (WHO)/International Society of Hypertension (ISH) statement on management of hypertension. J Hypertens 2003, 21(11):1983-1992.

19. Arima H, Tanizaki Y, Kiyohara Y, Tsuchihashi T, Kato I, Kubo M, Tanaka K, Ohkubo K, Nakamura H, Abe I, Fujishima M, lida M: Validity of the JNC VI recommendations for the management of hypertension in a general population of Japanese elderly: the Hisayama study. Arch Intern Med 2003, 163(3):361-366.

20. Major outcomes in high-risk hypertensive patients randomized to angiotensin-converting enzyme inhibitor or calcium channel blocker vs diuretic: The Antihypertensive and Lipid-Lowering Treatment to Prevent Heart Attack Trial (ALLHAT). JAMA 2002, 288(23):2981-2997.

21. Babad H, Sanderson C, Naidoo B, White I, Wang D: The development of a simulation model of primary prevention strategies for coronary heart disease. Health Care Management Science 2002, 5(4):269-274.

22. Japanese Society of Hypertension guidelines for the management of hypertension (JSH 2004). Hypertension Research 2006, 29(Suppl):S1-105.

23. Milchak JL, Carter BL, James PA, Ardery G: Measuring adherence to practice guidelines for the management of hypertension: an evaluation of the literature. Hypertension 2004, 44(5):602-608.

24. Sakamaki H, Kitazawa T, Muto T: [Study of clarifying incidence of lifestylerelated diseases and related complications and its medical expenses using government-managed health insurance data]. Nippon Eiseigaku Zasshi 2008, 63(3):651-661.

25. Neter JE, Stam BE, Kok FJ, Grobbee DE, Geleijnse JM: Influence of weight reduction on blood pressure: a meta-analysis of randomized controlled trials. Hypertension 2003, 42(5):878-884.

26. Burghes DN, Borrie MS: Modelling with Differential Equations. New York: Horwood; 1981.

27. Roumie $C L$, Elasy TA, Greevy R, Griffin MR, Liu X, Stone WJ, Wallston KA, Dittus RS, Alvarez V, Cobb J, Speroff T: Improving blood pressure control through provider education, provider alerts, and patient education: a cluster randomized trial. Ann Intern Med 2006, 145(3):165-175.

28. Lam AY: Assessing medication consultations, hypertension control, awareness, and treatment among elderly Asian community dwellers. Consult Pharm 2008, 23(10):795-803.

29. Fujii H, Muto T, Haruyama Y, Nakade M, Kobayashi E, Ishisaki K, Yamasaki A: Community-based lifestyle modification of cardiovascular disease risks in middle-aged Japanese: a 27-month update. Tohoku J Exp Med 220(4):307-318.

30. Harsha DW, Bray GA: Weight loss and blood pressure control (Pro). Hypertension 2008, 51(6):1420-1425.

31. Volpp KG, John LK, Troxel AB, Norton L, Fassbender J, Loewenstein G: Financial incentive-based approaches for weight loss: a randomized trial. JAMA 2008, 300(22):2631-2637.

32. Counterweight Project Team: Evaluation of the Counterweight Programme for obesity management in primary care: a starting point for continuous improvement. Brit J Gen Pract 2008, 58(553):548-554.

33. Ford ES, Zhao G, Li C, Pearson WS, Mokdad AH: Trends in obesity and abdominal obesity among hypertensive and nonhypertensive adults in the United States. Am J Hypertens 2008, 21(10):1124-1128. 
34. Poirier P, Giles TD, Bray GA, Hong Y, Stern JS, Pi-Sunyer FX, Eckel RH: Obesity and cardiovascular disease: pathophysiology, evaluation, and effect of weight loss: an update of the 1997 American Heart Association Scientific Statement on Obesity and Heart Disease from the Obesity Committee of the Council on Nutrition, Physical Activity, and Metabolism. Circulation 2006, 113(6):898-918.

35. Radak Z, Chung HY, Naito H, Takahashi R, Jung K, Kim HJ, Goto S: Ageassociated increase in oxidative stress and nuclear factor kappaB activation are attenuated in rat liver by regular exercise. FASEB Journal 2004, 18(6):749-750.

36. Takeuchi H, Saitoh S, Takagi S, Ohnishi H, Ohhata J, Isobe T, Shimamoto K: Metabolic syndrome and cardiac disease in Japanese men: applicability of the concept of metabolic syndrome defined by the National Cholesterol Education Program-Adult Treatment Panel III to Japanese men-the Tanno and Sobetsu Study. Hypertens Res 2005, 28(3):203-208.

37. Ohta Y, Tsuchihashi T, Fujii K, Matsumura K, Ohya Y, Uezono K, Abe I, lida M: Improvement of blood pressure control in a hypertension clinic: a 10-year follow-up study. J Hum Hypertens 2004, 18(4):273-278.

38. Saito I, Saruta T: Controlled release nifedipine and valsartan combination therapy in patients with essential hypertension: the adalat $C R$ and valsartan cost-effectiveness combination (ADVANCE-combi) study. Hypertension Research 2006, 29(10):789-796.

39. Chobanian AV, Bakris GL, Black HR, Cushman WC, Green LA, Izzo JL Jr, Jones DW, Materson BJ, Oparil S, Wright JT Jr, Roccella EJ: The Seventh Report of the Joint National Committee on Prevention, Detection, Evaluation, and Treatment of High Blood Pressure: the JNC 7 report. JAMA 2003, 289(19):2560-2572.

\section{Pre-publication history}

The pre-publication history for this paper can be accessed here: http://www.biomedcentral.com/1472-6947/11/8/prepub

doi:10.1186/1472-6947-11-8

Cite this article as: Ohno et al: Antihypertensive medication versus health promotion for improving metabolic syndrome in preventing cardiovascular events: a success rate-oriented simulation study. BMC Medical Informatics and Decision Making 2011 11:8.

\section{Submit your next manuscript to BioMed Central and take full advantage of:}

- Convenient online submission

- Thorough peer review

- No space constraints or color figure charges

- Immediate publication on acceptance

- Inclusion in PubMed, CAS, Scopus and Google Scholar

- Research which is freely available for redistribution

Submit your manuscript at www.biomedcentral.com/submit 